\title{
Disability and sexual and reproductive health service utilisation in Uganda: An intersectional analysis of Demographic and Health Surveys between 2006 and 2016
}

\author{
Muriel Mac-Seing ( $\square$ muriel.k.f.mac-seing@umontreal.ca ) \\ University of Montreal \\ Christina Zarowsky \\ University of Montreal \\ Mengru Yuan \\ McGill University \\ Kate Zinszer \\ University of Montreal
}

\section{Research Article}

Keywords: Keywords Determinants of health, disability, demographic and health surveys, sexual and reproductive health service utilisation, intersectionality, health equity, Uganda

Posted Date: April 12th, 2021

DOI: https://doi.org/10.21203/rs.3.rs-371936/v1

License: (c) (i) This work is licensed under a Creative Commons Attribution 4.0 International License. Read Full License 


\section{Abstract}

Background Universal health coverage, including sexual and reproductive health (SRH), pledges to "leave no one behind". However, people with disabilities continue to experience multiple barriers in accessing SRH services. Studies analysing the impacts of disability in conjunction with other social identities and health determinants reveal a complex pattern in SRH service use. Framed within a larger mixed methods study conducted in Uganda, we examined how disability, among other key social determinants of health (SDH), influenced the use of SRH services.

Methods We analysed data from repeated cross-sectional national surveys, the Uganda Demographic and Health Surveys (DHS) of 2006, 2011, and 2016. The three outcomes of interest were antenatal care visits, HIV testing, and modern contraception use. Our main exposure of interest was the type of disability, classified according to six functional dimensions: seeing, hearing, walking/climbing steps, remembering/concentrating, communicating, and self-care. We performed descriptive and multivariable logistic regression analyses. Regression analyses were informed by the intersectional framework to highlight social and health disparities withing groups.

Results From 2006 to 2016, 15.5-18.5\% of study participants lived with some form of disability. Over the same period, the prevalence of at least four antenatal care visits, HIV testing, and modern contraception use improved significantly. The DHS year, highest education level attained, and wealth index were the most consistent determinants of SRH service utilisation. People with different types of disabilities did not have the same SRH use patterns. Interactions between disability type and wealth index were associated with neither HIV testing nor the use of modern contraception. Women who were wealthy with hearing $(O R=0.15,95 \% \mathrm{Cl}$ $0.03-0.87)$ or with communication difficulty $(\mathrm{OR}=0.17,95 \% \mathrm{Cl} 0.03-0.82)$ had lower odds of having had optimal antenatal care visits compared to women without disabilities who were poorer.

Conclusion This study provided evidence that SRH service use improved over time in Uganda and highlight the importance of studying SRH and the different disability types when examining SDH. The SDH are pivotal to the attainment of universal health coverage, including SRH services, for all people irrespective of their social identities.

\section{Introduction}

Heads of State at the United Nations (UN)'s 2019 High-Level Meeting reaffirmed their commitment to Sustainable Developmental Goal (SDG) 3.8 on universal health coverage (UHC), including equitable access for all to sexual and reproductive health (SRH) services and information [1]. Although UHC pledges to "leave no one behind", disability is not a focus of the UHC despite being an important dimension of inclusion for the SDGs [2]. Globally, $15 \%$ of the world's population is estimated to live with some form of disability (physical, sensory, intellectual, and mental), with $80 \%$ of these individuals residing in low- and middle-income countries (LMIC) [3]. According to several studies conducted in LMICs, women, men, and youth with disabilities continue to experience multiple barriers in accessing SRH services such as antenatal care, contraception, HIV testing, and SRH information [4-10]. Although there is limited literature documenting the situation of people with disabilities beyond the focus on "medical and rehabilitative provision for conflict-related direct physical 
impairment" [11], it is suggested that in conflict or post-conflict settings, women with disabilities can face an additional risk of violence from community members [12]. A recent systematic review conducted in 11 subSaharan countries reported that people with disabilities faced multiple barriers to accessing SRH services, spanning the individual to the community, healthcare system, and economic levels [13].

Due to the multiple challenges experienced, people with disabilities have been reported to have poorer health outcomes $[3,14]$. The literature identifies numerous determinants that influence access to SRH services. They include women's age [15], education level $[15,16]$ and marital status [15] as well as the location of residence $[15,17]$, and level of household wealth $[15,16,18,19]$. However, studies analysing the impacts of disability in conjunction with other key social identities $[6,20,21]$ reveal a more nuanced pattern of associations with selected SRH utilisation outcomes. A cross-sectional study conducted in Sierra Leone found no significant difference between women with disabilities and those without disabilities when they sought maternal healthcare services, such as contraception use [20]. Using data from the Demographic and Health Survey (DHS), another study examined antenatal care among women with and without disabilities in Pakistan [6]. It reported that the overall measure of disability showed no association with antenatal care, while women with any severe disability had higher odds of receiving advice on exclusive breastfeeding than non-disabled women. In Cameroon, a study that was conducted among people with and without disabilities reported that although people with disabilities were at higher risk of poorer access to SRH services, disparities varied based on gender and disability [21]. The results of this study demonstrated that both women and men with disabilities had lower use of family planning and HIV testing that were not associated with access to SRH services, but were attributed to other factors associated with determinants related to respondents' childhood, such as poorer access to education and work opportunities [21].

The Northern region of Uganda was most affected by two decades (1987-2006) of armed conflict in Uganda, with persisting weakened socioeconomic and health systems [22]. In 2006, when the conflict ended, the Disability Act was also adopted in Uganda to protect and promote the rights of people with disabilities [23]. Framed within this background of conflict and access to health services, we were interested to examine how disability, among other social determinants of health, influences the use of SRH services. A parallel qualitative study found that adult women and men with disabilities living in Northern Uganda faced multiple challenges when using SRH services such as maternal care, contraception use, and HIV testing [24]. That study used an intersectionality-informed analysis to explore the co-existence of multiple social identities and social and health inequities experienced by vulnerable populations [25]. Major themes from the study included the complex intersections of disability with gender, HIV, and experience of violence [24]. The main objective of this present study was to investigate how disability was associated with selected SRH service utilisation in Uganda between 2006 and 2016. In addition, we looked at the interactions between disability type and sex, education, wealth, and violence.

\section{Methods}

\section{Study design and population}


We analysed data from repeated cross-sectional surveys from Uganda DHS of 2006, 2011, and 2016. These three waves of national DHS were representative surveys at the regional level, using a stratified two-stage sample design [26-28]. Administratively, in the 2006 DHS, there were nine regions: Kampala (the capital), North, Central 1, Central 2, East Central, Eastern, West Nile, Western, and Southwest. In the 2011 DHS, the Northern region was split into two, adding a tenth region, Karamoja. In the 2016 DHS, these 10 regions were further divided into 15 regions, while keeping the outer geographical boundaries of 2006.

Given the importance of the experience of violence expressed by people with disabilities in our qualitative study [24], this study included participants who answered the Domestic Violence Module within each DHS which focused on adult women and men, aged 18 to 49 years old. In the 2006 DHS, one female participant in every three households responded to the Module questions, while one male respondent was selected among the remaining two households [26]. In the 2011 DHS, one woman per household was selected among the two-third of the households, while one man per household was selected in the one-third of the households [27]. In the 2016 DHS, all households were invited to participate in the Module: one woman per household was randomly selected in two-thirds of the households, and in the remaining one-third of the households, a man per household responded to the questions [28]. In all three DHS, ever-married people were eligible for the Domestic Violence Module. Among these, when privacy was ensured during the interviews, they answered questions related to emotional, physical, and sexual violence, as part of the Module [26-28]. The participation rate was $96.2 \%, 99.3 \%$, and $99 \%$ among eligible women and $98.2 \%, 98.8 \%$, and $99 \%$ among eligible men, in 2006, 2011, and 2016, respectively [26-28]. The main reason reported for the nonparticipation of eligible people was the lack of privacy to complete the Domestic Violence Module [26-28].

The study population included ever-married people aged 18-49 years old for a total of 7,823 women for antenatal care visits, 10,754 women and 4,985 men for HIV testing, and 10,751 women and 4,982 men for contraception use over the three waves of data collection (Figure 1).

\section{Variables}

The three outcomes included: 1) antenatal care visits for the last pregnancy, 2) HIV testing during the past year, and 3 ) use of current type contraception type. The total number of antenatal care visits during their last pregnancy was recategorized as a binary variable based on the World Health Organization's

recommendation of at least four antenatal care visits for a positive pregnancy [29]: 0 for "0-3 antenatal care visits", and 1 for " 4 or more antenatal visits". The HIV testing variable, which asked whether respondents have ever been tested for HIV during the past year of the survey, kept its binary form ( $0=$ no, $1=y e s)$. For the current use of contraception method variable, participants were asked which method they were currently using at the time of the survey. Modern types of contraception (such as pills, injectables, male/female condoms and sterilisation, intrauterine devices, hormonal implants, and emergency contraception) were grouped together versus other methods (No use/use of traditional or folkloric contraception).

The main exposure variable of interest was the disability status, captured in the DHS as a 'difficulty' and following the Washington Group Short Set of Disability (WG) Questions [30]. The WG disability questions examined six functional dimensions: 1) seeing, 2) hearing, 3) walking or climbing steps, 4) remembering or concentrating, 5) self-care, and 6) communication, and according to four main levels of difficulty for each 
functional dimension: "No difficulty", "Some difficulty", "A lot of difficulty", and "Cannot do it at all". Disability type was recoded in a binary variable: 0 as "No difficulty", and 1 as "At least some difficulty and above" which also included people who were reported to have severe difficulties in any of the functional dimensions.

Sensitivity analyses were conducted for antenatal care visits and disability, to examine if and how their categorization influenced the estimated effect measures. Other variables of interest included sex, age, marital status, region, highest education level attained, wealth index, religion, and year of DHS. In addition, the experience of emotional, physical, and sexual violence was included as women and men with disabilities reported being at risk of and/or having experienced different forms of violence [24].

\section{Statistical analysis}

DHS datasets were made publicly available after the Uganda Bureau of Statistics processed and cleaned the data [26-28]. Data management, descriptive analyses, and multiple variable logistic regressions were conducted in R software (version 3.6.3) [31] and QGIS software (version 3.14) was used to produce bivariate choropleth maps [32]. Less than $1 \%$ of responses for outcomes were missing (respondents did not answer or did not know the answer) and were excluded from analyses. Descriptive analyses examined outcomes and exposure variables of interest at each time point. Bivariate choropleth maps were generated to examine how the overall disability status and outcomes of interest evolved by region between 2006 and 2016. To ensure comparability between the three different survey waves, we used the 2006 boundaries. Multivariable logistic regressions were created for each outcome of interest whereas a regional variable was created as well as survey year. Logistic regressions were adjusted for the two-stage sampling design used in the DHS using the 'survey' package in R. Variables with a Variance Inflation Factor (VIF) higher than 10, indicating the presence of multicollinearity, were excluded from analyses [33]. Given the intersectional approach adopted in our larger mixed methods study, key interaction terms ('intersections') informed by the qualitative findings were explored, emphasising the 'multiplicative' nature of people's identities [34]. Specifically, we looked at interaction terms between disability type and each of the following: sex, education, wealth index, and experience of emotional, physical, and sexual violence. The selection of final models was based on the Akaike Information Criterion (AIC) and the residuals were examined for model fit [35]. In the three outcome models, we present final outputs and interaction terms of interest.

\section{Results}

Table 1 summarises the socioeconomic characteristics of the study populations for selected SRH service use for the period between 2006 and 2016 in Uganda. The majority of respondents were women, ranging from $68.3 \%$ for HIV testing and use of modern contraception to $100 \%$ of respondents for antenatal care visits since direct maternal care only targeted women. Among the ever-married adult respondents of reproductive age (18-49 years old), approximately $11 \%$ were separated/divorced/widowed. Across SRH service use, $15.5-18.5 \%$ lived with some form of disability in at least one of the functional dimensions. Regarding difficulty type, $7.1-8.6 \%$ of respondents were reported having at least some difficulty in walking or climbing steps, and $7.6-8.6 \%$ had at least some difficulty in remembering or concentrating. People were also 
reported to have had at least some difficulty in seeing (2.7-4.0\%), in hearing (1.2-1.4\%), and in self-care (0.5$1.3 \%$ ). Approximately $80 \%$ people lived in rural areas, had primary education (60.1-61.2\%), and were of Anglican, Catholic, or Muslim faith. Approximately two-thirds of respondents were situated in the three lowest wealth quintiles. Approximately $40 \%$ of respondents experienced emotional violence, $35.8-42.8 \%$ faced physical violence, and 19.4-25.1\% reported sexual violence.

Table 1 Characteristics of population by SRH service in Uganda (2006-2016) 


\begin{tabular}{|c|c|c|}
\hline & $\begin{array}{l}\text { Antenatal care } \\
\text { visits } \\
(\mathrm{N}=7,823)\end{array}$ & $\begin{array}{l}\text { HIV testing and use of modern contraception } \\
\text { type } \\
\qquad\left(\mathrm{N}=15,739^{\mathrm{a}}\right)\end{array}$ \\
\hline \multicolumn{3}{|l|}{ Sex } \\
\hline Women & 100 & 68.3 \\
\hline \multicolumn{3}{|l|}{ Age in years } \\
\hline $18-19$ & 5.4 & 3.9 \\
\hline $\begin{array}{l}20-24 \\
25-29\end{array}$ & 26.2 & 18.4 \\
\hline $\begin{array}{l}25-29 \\
30-34\end{array}$ & $\begin{array}{l}26.5 \\
20.8\end{array}$ & $\begin{array}{l}21.4 \\
20.4\end{array}$ \\
\hline $35-39$ & 13.1 & 15.7 \\
\hline 40 and $>$ & & \\
\hline \multicolumn{3}{|l|}{ Marital status } \\
\hline Married/in union & 89.3 & 87.1 \\
\hline $\begin{array}{l}\text { Separated / divorced / } \\
\text { widowed }\end{array}$ & 10.7 & 12.9 \\
\hline \multicolumn{3}{|l|}{ Disability } \\
\hline Overall & 15.5 & 18.5 \\
\hline Difficulty seeing & 2.7 & 4.0 \\
\hline Difficulty hearing & 1.2 & 1.4 \\
\hline $\begin{array}{l}\text { Difficulty walking / } \\
\text { climbing steps }\end{array}$ & 7.1 & 8.6 \\
\hline Difficulty remembering / & 7.6 & 8.6 \\
\hline concentrating & 0.8 & 1.1 \\
\hline Difficulty with self-care & 0.9 & 1.2 \\
\hline \multirow{2}{*}{\multicolumn{3}{|c|}{$\begin{array}{l}\text { Difficulty } \\
\text { communicating }\end{array}$}} \\
\hline & & \\
\hline \multicolumn{3}{|c|}{ Highest education level attained } \\
\hline No education & 15.9 & 13.6 \\
\hline Primary & 61.2 & 60.1 \\
\hline Secondary & 18.2 & 19.3 \\
\hline Higher & 4.7 & 7.0 \\
\hline \multicolumn{3}{|l|}{ Wealth index } \\
\hline Quintile 1 (poorest) & 26.1 & 23.3 \\
\hline Quintile 2 (poorer) & 22.1 & 21.1 \\
\hline Quintile 3 (middle) & 18.2 & 18.4 \\
\hline Quintile 4 (richer) & 16.8 & 18.0 \\
\hline \multirow{2}{*}{\multicolumn{3}{|c|}{$\begin{array}{l}\text { Religion } \\
\text { Renticnest) }\end{array}$}} \\
\hline & & \\
\hline Anglican & 35.5 & 36.5 \\
\hline Catholic & 37.3 & 38.2 \\
\hline Muslim & 12.7 & 11.9 \\
\hline \multicolumn{3}{|l|}{ Pentecostal / Born Again } \\
\hline I & & \\
\hline $\begin{array}{l}\text { Evangelical } \\
\text { Other }\end{array}$ & 2.0 & 1.9 \\
\hline \multicolumn{3}{|l|}{ Place of residence } \\
\hline Rural & 81.7 & 79.9 \\
\hline \multicolumn{3}{|l|}{ Region } \\
\hline Kampala & 5.4 & 6.2 \\
\hline North & 19.0 & 18.0 \\
\hline Central 1 & 8.4 & 8.8 \\
\hline Central 2 & 8.5 & 8.9 \\
\hline East Central & 9.4 & 9.3 \\
\hline Eastern & 16.5 & 16.0 \\
\hline West Nile & 8.3 & 7.9 \\
\hline Western & 12.0 & 12.2 \\
\hline Southeast & 12.5 & 12.5 \\
\hline \multicolumn{3}{|l|}{ Experience of violence } \\
\hline
\end{tabular}


${ }^{a}$ For the use of modern contraception type, there are six people less, N=15,733

\section{Determinants of sexual and reproductive health service utilisation}

In Table 2, the disability type was not associated with the SRH service use, except for people with difficulty in communicating who had lower odds of having used modern contraception compared to people without disabilities $(\mathrm{OR}=0.51,95 \% \mathrm{Cl} 0.29-0.90)$. Women had higher odds of being tested for HIV $(\mathrm{OR}=2.76$, $95 \% \mathrm{Cl} 2.38-3.21$ ), while sex was not associated with the use of modern contraception. People who were separated, divorced, or widowed had lower odds of having had the optimal number of antenatal care visits $(\mathrm{OR}=0.76,95 \% \mathrm{Cl} 0.63-0.90)$ and to have used modern contraception $(\mathrm{OR}=0.76,95 \% \mathrm{Cl} 0.67-0.86)$ relative to married/in union participants. Violence of any type was not associated with either the use of antenatal care or HIV testing. However, participants who experienced emotional $(\mathrm{OR}=1.22,95 \% \mathrm{Cl} 1.11-$ $1.34)$ and physical violence $(\mathrm{OR}=1.15,95 \% \mathrm{Cl} 1.04-1.27)$ were more likely to have used modern contraception.

Table 2 Multiple logistic regression models on sexual and reproductive health use 


\begin{tabular}{|c|c|c|c|c|c|c|}
\hline & \multicolumn{2}{|c|}{$\begin{array}{c}\text { Model I } \mathrm{I}^{\mathrm{a}} \text { : } \\
\text { At least four } \\
\text { antenatal care visits }\end{array}$} & \multicolumn{2}{|c|}{$\begin{array}{l}\text { Model } \mathrm{II}^{\mathrm{b}}: \\
\text { HIV testing }\end{array}$} & \multicolumn{2}{|c|}{$\begin{array}{c}\text { Model III } \\
\text { Modern } \\
\text { contraception } \\
\text { type use }\end{array}$} \\
\hline & OR & $95 \% \mathrm{CI}$ & OR & $\begin{array}{l}95 \% \\
\mathrm{CI}\end{array}$ & OR & $\begin{array}{l}95 \% \\
\mathrm{CI}\end{array}$ \\
\hline $\begin{array}{l}\text { Disability (Ref }{ }^{\mathrm{d}} \text { : No difficulty) } \\
\text { Difficulty seeing }\end{array}$ & 1.09 & $\begin{array}{l}0.76- \\
1.57\end{array}$ & 1.17 & $\begin{array}{l}0.82- \\
1.66\end{array}$ & 0.98 & $\begin{array}{l}0.70 \\
-\end{array}$ \\
\hline Difficulty hearing & 0.60 & $\begin{array}{l}0.19- \\
1.89\end{array}$ & 1.64 & $\begin{array}{l}0.89- \\
3.03\end{array}$ & 1.19 & $\begin{array}{l}1.39 \\
0.66 \\
-\end{array}$ \\
\hline Difficulty walking / climbing steps & 1.22 & $\begin{array}{l}0.99- \\
1.49\end{array}$ & 0.90 & $\begin{array}{l}0.63- \\
1.29\end{array}$ & 1.29 & $\begin{array}{l}2.17 \\
0.98 \\
-\end{array}$ \\
\hline $\begin{array}{l}\text { Difficulty remembering / } \\
\text { concentrating }\end{array}$ & 0.85 & $\begin{array}{l}0.70- \\
1.05\end{array}$ & 0.94 & $\begin{array}{l}0.68- \\
1.30\end{array}$ & 1.05 & $\begin{array}{l}1.71 \\
0.82 \\
-\end{array}$ \\
\hline Difficulty in self-care & 1.32 & $\begin{array}{l}0.75- \\
2.32\end{array}$ & 0.45 & $\begin{array}{l}0.15- \\
1.37\end{array}$ & 1.37 & $\begin{array}{l}1.34 \\
0.67 \\
-\end{array}$ \\
\hline Difficulty in communicating & 1.54 & $\begin{array}{l}0.34- \\
6.90\end{array}$ & 0.62 & $\begin{array}{l}0.20 \\
-1.96\end{array}$ & $0.51 * \mathrm{e}$ & $\begin{array}{l}2.80 \\
0.29 \\
- \\
0.90\end{array}$ \\
\hline $\begin{array}{l}\text { Year (Ref: 2006) } \\
2011\end{array}$ & 1.03 & $\begin{array}{l}0.85- \\
1.25\end{array}$ & $8.78 * * *$ & $\begin{array}{l}7.37- \\
10.46\end{array}$ & $1.41 * * *$ & 1.21 \\
\hline 2016 & $1.62^{* * *}$ & $1.38-1.89$ & $29.31 * * *$ & $\begin{array}{l}24.93 \\
- \\
34.45\end{array}$ & $2.29 * * *$ & $\begin{array}{l}1.99 \\
- \\
2.63\end{array}$ \\
\hline $\begin{array}{l}\text { Sex (Ref: Man for Models II and III) } \\
\text { Woman }\end{array}$ & - & - & $2.76 * * *$ & $\begin{array}{l}2.38- \\
3.21\end{array}$ & 0.93 & $\begin{array}{l}0.84 \\
- \\
1\end{array}$ \\
\hline $\begin{array}{l}\text { Marital status (Ref: Married / in } \\
\text { union) } \\
\text { Separated / divorced / widowed }\end{array}$ & $0.76^{* *}$ & $\begin{array}{l}0.63- \\
0.90\end{array}$ & 0.88 & $\begin{array}{l}0.74- \\
10.4\end{array}$ & $0.76 * * *$ & $\begin{array}{l}0.67 \\
- \\
0.86\end{array}$ \\
\hline $\begin{array}{l}\text { Religion (Ref: Anglican) } \\
\text { Catholic }\end{array}$ & - & - & - & - & 0.92 & 0.84 \\
\hline Muslim & - & - & - & - & $0.81 * *$ & $\begin{array}{l}1.02 \\
0.70 \\
-\end{array}$ \\
\hline $\begin{array}{l}\text { Seven Day Adventist / Pentecostal / } \\
\text { Born Again / Evangelical }\end{array}$ & - & - & - & - & $0.76^{* * *}$ & $\begin{array}{l}0.94 \\
0.66 \\
-\end{array}$ \\
\hline Other & - & - & - & - & $0.63 * *$ & $\begin{array}{l}0.86 \\
0.45 \\
- \\
0.88\end{array}$ \\
\hline $\begin{array}{l}\text { Highest education (Ref: No } \\
\text { education) } \\
\text { Primary }\end{array}$ & 1.10 & $\begin{array}{l}0.93- \\
1.30\end{array}$ & $1.82 * * *$ & $\begin{array}{l}1.53- \\
2.15\end{array}$ & $1.88 * * *$ & $\begin{array}{l}1.60 \\
-\end{array}$ \\
\hline Secondary and higher & $1.43^{* * *}$ & $\begin{array}{l}1.18- \\
1.87\end{array}$ & $3.46^{* * *}$ & $\begin{array}{l}2.75- \\
4.34\end{array}$ & $2.32 * * *$ & $\begin{array}{l}2.21 \\
1.92 \\
-\end{array}$ \\
\hline
\end{tabular}


Wealth index (Ref: Quintile 1

Poorest)

Quintile 2 (poorer)

$1.20 * \quad 1.01-$

1.42

Quintile 3 (middle)

$1.22 \quad 1.00-$

1.48

Quintile 4 (richer)

$1.48^{* * *} \quad 1.22-$

Quintile 5 (richest)

$\begin{array}{ll}1.81^{* * *} & 1.41 \\ 2.33\end{array}$

$\begin{array}{ll}1.02 \quad 0.84- \\ & 1.22\end{array}$

Region (Ref: Urban)

Rural

$\begin{array}{ll}1.13 & 0.82- \\ & 1.57\end{array}$

Region (Ref: Kampala)

North

Central 1

0.88

$0.63-$

1.24

Central 2

$0.75 \quad 0.54-$

1.03

East Central

$\begin{array}{ll}1.02 \quad 0.73 \\ & 1.43\end{array}$

Eastern

0.79

$0.57-$

1.09

$1.52 * \quad 1.05-$

2.21

0.94

$0.67-$

1.31

$1.04 \quad 0.75-$

1.43

$\begin{array}{lll}1.11 \quad 0.98- & 1.06\end{array}$

Experienced violence (Ref: No)

Emotional violence

1.25

$0.90 \quad 0.78-$

1.02

0.92

0.76

0.85

0.75

1.36

Physical violence

$0.93 \quad 0.81-$
1.06

0.91

Sexual violence

$$
1.06
$$

0.86

0.79

0.71
1.21

0.96
1.35

$1.41 * * *$

1.22

1.61

$1.15-1.58^{* * *} 1.37$

1.69

$-$

1.84

$1.33-1.99 * * * \quad 1.70$

2.06

2.33

$2.10-2.09 * * *$

1.73

$\overline{2} .52$

0.74

0.996

0.74

$0.99-0.95$

$-$

1.22

0.65

$0.50-0.83$

1.16

$-$

1.07

$0.57-1.15 \quad 0.91$

1.28

$-$

1.45

$0.41-\quad 0.75 * \quad 0.57$

0.93

0.97

$0.50-0.96 \quad 0.76$

1.14

$-$

1.20

$0.88 \quad 0.50 * * *$

0.38

$-2.10$

$\overline{0} .67$

0.70

$0.58-0.89$

1.28

$-$

1.13

$0.53-0.80 \quad 0.63$

1.18

$\overline{1} .02$

Disability type*Sex (Ref: Man and without any type of difficulty)

Difficulty seeing*Sex

$0.56^{*}$

$0.93-1.22^{* * *}$

1.11

1.21

1.34

1.04

0.80
1.06 $-$

Difficulty in self-care*Sex

3.58*

0.35

$0.79-$

1.05

Disability type*Education (Ref: Without disability and no education)

$1.23-0.41$
10.38

0.85

2.09

0.17

$\overline{1} .01$ 


\begin{tabular}{|c|c|c|c|c|c|c|}
\hline $\begin{array}{l}\text { Difficulty hearing*Secondary } \\
\text { education and higher }\end{array}$ & $10.84^{*}$ & $\begin{array}{l}10.53 \\
1.67- \\
70.54\end{array}$ & - & - & - & - \\
\hline \multicolumn{7}{|c|}{ Disability type*Wealth index (Ref: Without any type of difficulty and poorer) } \\
\hline Difficulty hearing*Poor & 0.37 & $\begin{array}{l}0.10- \\
1.37\end{array}$ & 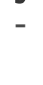 & - & - & - \\
\hline Difficulty hearing*Middle & 1.01 & $\begin{array}{l}0.24- \\
4.16\end{array}$ & - & - & - & - \\
\hline Difficulty hearing*Rich & $0.15 *$ & $\begin{array}{l}0.03- \\
0.87\end{array}$ & - & - & - & - \\
\hline Difficulty hearing*Richer & $0.16 *$ & $\begin{array}{l}0.03- \\
0.89\end{array}$ & - & - & - & - \\
\hline Difficulty in communicating*Poor & 0.23 & $\begin{array}{l}0.05- \\
1.15\end{array}$ & - & - & - & - \\
\hline Difficulty in communicating*Middle & 0.48 & $\begin{array}{l}0.07- \\
3.42\end{array}$ & - & - & - & - \\
\hline Difficulty in communicating*Rich & $0.17^{*}$ & $\begin{array}{l}0.03- \\
0.82\end{array}$ & - & - & - & - \\
\hline Difficulty in communicating*Richer & 0.90 & $\begin{array}{l}0.07- \\
12.32\end{array}$ & - & - & - & - \\
\hline
\end{tabular}

a Adjusted for disability type, year, marital status, residence, region, education, wealth index, age, and violence

${ }^{b}$ Adjusted for disability type, year, sex, marital status, residence, region, education, wealth index, age, and violence

${ }^{\mathrm{c}}$ Adjusted for disability type, year, sex, marital status, religion, residence, region, education, wealth index, age, and violence

$\mathrm{d}$ Reference group $\quad \mathrm{e} * \mathrm{p}<0.05, * * \mathrm{p}<0.01, * * * \mathrm{p}<0.001$ in two-tailed tests of significance

There were three covariates that showed a consistent association with the SRH service use: the DHS year, education level, and wealth index. Compared to 2006, the year 2016 showed higher odds of having had at least four antenatal care visits $(\mathrm{OR}=1.62,95 \% \mathrm{Cl} 1.38-1.89)$, of being tested for HIV $(\mathrm{OR}=29.31,95 \% \mathrm{Cl}$ $24.93-34.35)$, and having used modern contraception ( $O R=2.29,95 \% \mathrm{Cl} 1.99-2.63)$. Having at least a primary education led to higher odds of being tested for HIV $(\mathrm{OR}=1.82,95 \% \mathrm{Cl} 1.53-2.15)$ and having used modern contraception $(\mathrm{OR}=1.88,95 \% \mathrm{Cl} 1.60-2.21)$, while having at least a secondary education increased the likelihood of having had the optimal number of antenatal care visits $(\mathrm{OR}=1.43,95 \% \mathrm{Cl} 1.18-1.87)$.

Regarding the wealth index, the increasing wealth quintiles were positively associated with utilisation of all three SRH services: participants who were richest had higher odds than those who were among the poorest to have had at least four antenatal care visits $(\mathrm{OR}=1.81,95 \% \mathrm{Cl} 1.41-2.33)$, tested for HIV $(\mathrm{OR}=2.80$, $95 \% \mathrm{Cl} 2.10-3.73)$ or used modern contraception type ( $\mathrm{OR}=2.09,95 \% \mathrm{Cl} 1.73-2.52)$.

Religion and region of residence were also significantly associated with $\mathrm{SRH}$ service use. Muslims (OR = $0.81,95 \% \mathrm{Cl} 0.70-0.94)$ or the Seven Day Adventist/Pentecostal/Born Again/Evangelical $(\mathrm{OR}=0.76,95 \% \mathrm{Cl}$ $0.66-0.86$ ) faith were less likely to have used modern contraception compared to Anglicans, while the Catholic faith did not show any significant association with any of the SRH service use. Women living in West Nile had higher odds of having had at least four antenatal care visits $(\mathrm{OR}=1.52,95 \% \mathrm{Cl} 1.05-2.21)$, 
while they had lower odds of having used modern contraception ( $O R=0.50,95 \% \mathrm{Cl} 0.38-0.67)$ compared to people living in the capital. People in East Central were less likely to be tested for HIV $(\mathrm{OR}=0.62,95 \% \mathrm{Cl} 0.41$ $-0.93)$ and having used modern contraception $(\mathrm{OR}=0.75,95 \% \mathrm{Cl} 0.57-0.07)$. People living in rural areas were less likely to have used modern contraception $(\mathrm{OR}=0.86,95 \% \mathrm{Cl} 0.74-0.996)$.

The sensitivity analyses did not reveal any significant differences in the measures of association. The categorization of disability, antenatal care visits, and the use of modern contraception type did not influence the measures of association.

\section{Effects of interaction terms}

In the final models (Table 2), a few interaction terms were statistically significant. Among interactions between disability type and sex, women with difficulty in seeing were less likely to have had HIV testing (OR = $0.56,95 \% \mathrm{Cl} 0.35-0.90)$ compared to men without seeing difficulty, while women with difficulty with selfcare had higher odds to have been tested for $\mathrm{HIV}(\mathrm{OR}=3.68,95 \% \mathrm{Cl} 1.23-10.38)$. Among interactions between disability type and education, only women with hearing difficulty and who had a least secondary education were more likely than women without education to have had at least four and more antenatal care visits $(\mathrm{OR}=10.84,95 \% \mathrm{Cl} 1.67-70.54)$. For interactions of disability type and wealth index, women with difficulty reading in the fourth $(\mathrm{OR}=0.15,95 \% \mathrm{Cl} 0.03-0.87)$ and fifth $(\mathrm{OR}=0.16,95 \% \mathrm{Cl} 0.03-0.89)$ quintile of wealth index and women with difficulty in communicating in the fourth wealth index quintile (OR = $0.17,95 \% \mathrm{Cl} 0.03-0.82$ ) had lower odds of having had at least four antenatal care visits compared to women without any type of disability.

\section{Discussion}

This study found that SRH service use increased among the study population between 2006 and 2016, notably for HIV testing, and that the association of disability type and SRH service use was nuanced. Our results also demonstrate the importance of considering the intersections of vulnerabilities, such as disability, wealth, and sex, in quantitative analyses when examining social determinants of health.

Across all three SRH outcomes, the likelihood of service use increased from 2006 to 2016 . The years included in our analyses coincided with the 2000-2015 Millennium Development Goals (MDG) which focused on maternal health improvement (MDG 5) including contraception use and the fight against HIV and AIDS (MDG 6) [36]. Among the three outcomes, HIV testing recorded the sharpest increase in 2016 compared to previous years. This can likely be explained by additional HIV financing by The Global Fund in Uganda from 2001 to 2007 [37], and the continuous HIV and AIDS funding by the President's Emergency Plan for AIDS Relief (PEPFAR) from 2003 to date in sub-Saharan African countries, including Uganda [38]. However, disparities were observed among regions and across the different types of SRH services. Unequal healthcare coverage could potentially have contributed to these regional disparities coupled with slower performance in maternal health outcomes across the country and possibly reflecting a rural-urban divide [39].

Our findings showed that social determinants of health, such as education level $[15,16]$ and wealth $[15,16$, $18,19]$ were important determinants of SRH service use, with other studies having found that being religious 
$[40,41]$ and living in rural areas $[15,17]$ decreased the likelihood of using some types of SRH services, such as the use of modern contraception. Furthermore, our findings suggest the need to explore beyond individual social determinants of health and consider the multiple layers of coexisting factors. We found that including an interaction between the type of disability and other factors such as sex, education level and wealth was important to detect associations and health inequities that would have otherwise been missed. Other quantitative research on intersectionality highlighted the "danger of misunderstanding the nature of social experiences and identities manifested in specific contexts" [34] and the importance of adopting the "intersectionality [framework]'s core ideas of social inequality, power, relationality, social context, and complexity" into quantitative population health research drawing from the social sciences [42]. Based on our qualitative study, we learned from women and men with disabilities that they experienced multiple barriers and layers of discrimination in accessing and using SRH services in Northern Uganda [24].

Specifically, to better understand marginalised people's realities, the literature on intersectionality has further stressed the need to consider multiple level analysis, from the individual to the populational level [43]. In one of her seminal papers, "When Black + Lesbian + Woman \# Black Lesbian Woman" [44], Bowleg recommended examining the non-additive aspects of social identities and power dynamics such as racism, heterosexism, and sexism [43]. According to the context, vulnerable and marginalised people may simultaneously experience privileges on one hand (for example, based on their gender), and disadvantages on another hand (for example, based on race), hence looking beyond the additive aspects of social experiences. Our findings suggest that a rich woman with a hearing impairment had less chances of having had the optimal antenatal care. This is possibly due to the combined forces of ableism and other discriminatory power dynamics that could have prevented her to having used the services at the same frequency compared to other women with other impairments or non-disabled women.

Regarding the experience of violence, although emotional and physical violence were associated with an increased likelihood of using modern contraception, there was no significant interaction between disability and violence. This finding is in contrast to a recent study conducted in Uganda which showed that women with disabilities were significantly more likely to have experienced all forms of violence compared to women without disabilities [45]. Our study may have underestimated the association of the experience of any type of domestic violence on the use of SRH services, due to reasons such as fear of stigma [46] and also given that our study population included only ever-married people over the age of 18 years old. A systematic review on gender-based violence victimization in adolescent girls in LMICs reported that young people who were unmarried or married experienced different forms of violence, such as sexual violence, intimate partner violence, and child marriage [47].

\section{Limitations}

Our study has several limitations. The DHS data were collected through self-reporting from participants. However the information related to disability was obtained from the household head for all household members which might have introduced a bias in reporting each household member's type and level of difficulty in functional dimensions. Moreover, underlying power structures, such as ableism, were not examined in this study, which likely played a critical role in SRH service use, potentially due to multiple 
discriminatory barriers hindering the effective use of services among people with disabilities [24]. Intersectional scholarship posits that power systems both structure and reinforce social identities, and could be better understood through mixed methods [43], although qualitative data collection was not a methodological dimension included in the DHS. Finally, structured questionnaire designed for quantitative research, such as the DHS, is that these types of questionnaires are not designed to capture diverse societal interactions in various groups, such as people located at the margin of the society [48].

\section{Conclusion}

This study provided evidence that SRH outcomes improved over time in Uganda and highlight the importance of examining the social determinants of health when studying SRH and the different types of disability. Social determinants of health are pivotal to the attainment of the SDGs, notably SDG 3 which emphasises universal health coverage, including SRH services, for all people irrespective of their social identities. According to the United Nations' Convention on the Rights of Persons with Disabilities, disability results from the interactions between people with impairments (physical, sensory, intellectual, and mental) and barriers (physical, attitudinal and structural) in society that hinder their social participation [49]. Provided that accessible environments and/or enabling social determinants of health are present and that barriers are removed [3], people can fully exercise their rights and enjoy more positive health outcomes.

\section{List Of Abbreviations}

AIC Akaike Information Criterion

AIDS $\quad$ Acquired Immunodeficiency Syndrome

DHS Demographic and Health Survey

HIV Human Immunodeficiency Virus

LMIC Low- and Middle-Income Country

MDG Millennium Development Goals

PEPFAR President's Emergency Plan for AIDS Relief

SDG Sustainable Development Goals

SRH Sexual and Reproductive Health

UHC Universal Health Coverage

UN United Nations

VIF Variance Inflation Factor 


\section{Declarations}

\section{Ethics approval and consent to participate}

For this specific study using the DHS secondary data, ethics approval was not required since the data are available in the public domain. The larger mixed methods study which this study was part of was conducted in accordance with the Tri-Council Policy Statement: Ethical Conduct for Research Involving Humans (TCPS2) and received ethics approval from the Centre de recherche du Centre hospitalier de l'Université de Montréal (CR-CHUM) (17.127-CÉR, 1 August 2017) and the Research Ethics Committee in Sciences and Health of the Université de Montréal (CERCES-20-074-D, 13 May 2020).

\section{Consent for publication}

Not applicable since there are no details, images, or videos relating to any individual persons.

\section{Availability of data and materials}

The datasets used in this study are available online from the DHS Program at: https://dhsprogram.com/data/Using-Datasets-for-Analysis.cfm

\section{Competing interests}

None to declare

\section{Funding}

MMS received a doctoral training scholarship from the Fonds de Recherche du Québec - Santé (0000256736). The funding source had no role in the study design, data collection, analysis, and interpretation, or writing and preparation of the manuscript, or decision to publish. The content of this manuscript is solely the responsibility of the authors and does not necessarily represent the official views of funders.

\section{Authors' contributions}

MMS conceptualised the manuscript. MMS, MY and KZ analysed the data. All authors contributed to, reviewed, read, and approved the final manuscript.

\section{Acknowledgments}

Authors thank the DHS Program for their support in availing the datasets for analysis.

\section{References}

1. United Nations. Resolution adopted by the General Assembly on 10 October 2019. Political declaration of the high-level meeting on universal health coverage. UN. 2019. Available online: https://undocs.org/en/A/RES/74/2. Accessed 16 Oct 2020. 
2. Hashemi G, Kuper H, Wickenden M. SDGs, Inclusive Health and the path to Universal Health Coverage. Disability and The Global South. Disability and the Global South. 2017;4(1):1088-111.

3. World Health Organization, The World Bank. World report on disability. Malta: World Health Organization; 2011.

4. Ahumuza SE, Matovu JK, Ddamulira JB, Muhanguzi FK. Challenges in accessing sexual and reproductive health services by people with physical disabilities in Kampala, Uganda. Reproductive health. 2014;11(1):59.

5. Burke E, Kébé F, Flink I, van Reeuwijk M, le May A. A qualitative study to explore the barriers and enablers for young people with disabilities to access sexual and reproductive health services in Senegal.

Reproductive Health Matters. 2017;25(50):43-54. doi:10.1080/09688080.2017.1329607.

6. Hameed W, Asim M. Inequalities in utilization of essential antenatal services for women with disabilities. Rockville, Maryland, USA: ICF;2020.

7. Kassa TA, Luck T, Birru SK, Riedel-Heller SG. Sexuality and sexual reproductive health of disabled young people in Ethiopia. Sexually Transmitted Diseases. 2014;41(10):583-8.

doi:http://dx.doi.org/10.1097/OLQ.0000000000000182.

8. Mac-Seing $M$, Zarowsky $C$. Une méta-synthèse sur le genre, le handicap et la santé reproductive en Afrique subsaharienne. Santé Publique. 2017;29(6):909-19.

9. Parsons JA, Bond VA, Nixon SA. 'Are We Not Human?' Stories of Stigma, Disability and HIV from Lusaka, Zambia and Their Implications for Access to Health Services. PLoS ONE [Electronic Resource]. 2015;10(6):e0127392. doi:http://dx.doi.org/10.1371/journal.pone.0127392.

10. Tanabe M, Nagujjah Y, Rimal N, Bukania F, Krause S. Intersecting Sexual and Reproductive Health and Disability in Humanitarian Settings: Risks, Needs, and Capacities of Refugees with Disabilities in Kenya, Nepal, and Uganda. Sexuality and Disability. 2015;33(4):411-27. doi:10.1007/s11195-015-9419-3.

11. Berghs M, Kabbara N. Disabled People in Conflicts and Wars. In: Grech S, Soldatic K, editors. Disability in the Global South: The Critical Handbook. Cham: Springer International Publishing; 2016. p. 269-83.

12. Frohmader $\mathrm{C}$, Ortoleva $\mathrm{S}$, editors. The sexual and reproductive rights of women and girls with disabilities. ICPD International Conference on Population and Development Beyond; 2014. North Hobath.

13. Ganle JK, Baatiema L, Quansah R, Danso-Appiah A. Barriers facing persons with disability in accessing sexual and reproductive health services in sub-Saharan Africa: A systematic review. PLOS ONE. 2020;15(10):e0238585. doi:10.1371/journal.pone.0238585.

14. Kuper $\mathrm{H}$, Hanefeld J. Debate: can we achieve universal health coverage without a focus on disability? BMC Health Services Research. 2018;18(1):738. doi:10.1186/s12913-018-3547-2.

15. Guliani H, Sepehri A, Serieux J. Determinants of prenatal care use: Evidence from 32 low-income countries across Asia, Sub-Saharan Africa and Latin America. Health policy and planning. 2013;29(5):589-602.

16. Sialubanje C, Massar K, Hamer DH, Ruiter RA. Personal and environmental predictors of the intention to use maternal healthcare services in Kalomo, Zambia. Health education research. 2014;29(6):1028-40. 
17. Alam N, Hajizadeh M, Dumont A, Fournier P. Inequalities in maternal health care utilization in subsaharan african countries: a multiyear and multi-country analysis. PloS one. 2015;10(4):e0120922.

18. Memirie ST, Verguet S, Norheim OF, Levin C, Johansson KA. Inequalities in utilization of maternal and child health services in Ethiopia: the role of primary health care. BMC health services research. 2016;16(1):1.

19. Kiwanuka S, Ekirapa E, Peterson S, Okui O, Rahman MH, Peters D et al. Access to and utilisation of health services for the poor in Uganda: a systematic review of available evidence. Transactions of the Royal Society of Tropical Medicine and Hygiene. 2008;102(11):1067-74.

20. Trani JF, Browne J, Kett M, Bah O, Morlai T, Bailey N et al. Access to health care, reproductive health and disability: a large scale survey in Sierra Leone. Social Science \& Medicine. 2011;73(10):1477-89. doi:http://dx.doi.org/10.1016/j.socscimed.2011.08.040.

21. DeBeaudrap P, Mouté C, Pasquier E, Mac-Seing M, Mukangwije PU, Beninguisse G. Disability and access to Sexual and Reproductive Health services in Cameroon: A mediation analysis of the role of socioeconomic factors. International journal of environmental research and public health. 2019;16(3):417.

22. Chi PC, Bulage $P$, Urdal $H$, Sundby J. A qualitative study exploring the determinants of maternal health service uptake in post-conflict Burundi and Northern Uganda. BMC Pregnancy and Childbirth. 2015;15(1):18. doi:10.1186/s12884-015-0449-8.

23. Republic of Uganda. Persons with disabilities Act. 2006.

24. Mac-Seing M, Zinszer K, Eryong B, Ajok E, Ferlatte O, Zarowsky C. The intersectional jeopardy of disability, gender and sexual and reproductive health: Experiences and recommendations of women and men with disabilities in Northern Uganda. Sexual and Reproductive Health Matters. 2020:1-27. doi:10.1080/26410397.2020.1772654.

25. Hankivsky O, Grace D, Hunting G, Giesbrecht M, Fridkin A, Rudrum S et al. An intersectionality-based policy analysis framework: critical reflections on a methodology for advancing equity. International journal for equity in health. 2014;13(1):119.

26. Uganda Bureau of Statistics (UBOS), ICF International Inc. Uganda Demographic Health Survey 2006. Kampala, Uganda and Calverton, Maryland: Uganda Bureau of Statistics (UBOS), ICF International Inc.;2007.

27. Uganda Bureau of Statistics (UBOS), ICF International Inc. Uganda Demographic and Health Survey 2011. Kampala, Uganda and Calverton, Maryland: Uganda Bureau of Statistics (UBOS), ICF International Inc.;2012.

28. Uganda Bureau of Statistics (UBOS), ICF International Inc. Uganda Demographic Health Survey 2016. Kampala, Uganda; Calverton, Maryland: Uganda Bureau of Statistics (UBOS) and ICF International Inc.;2018.

29. WHO, Human Reproduction Programme. New guidelines on antenatal care for a positive pregnancy experience. WHO. 2016. Available online: https://www.who.int/reproductivehealth/news/antenatalcare/en/. Accessed 9 October 2020. 
30. Casebolt MT. Availability and quality of global disability data: A commentary on the Demographic and Health Surveys. Disability and Health Journal. 2020:100972.

doi:https://doi.org/10.1016/j.dhjo.2020.100972.

31. R. The R project for statistical computing. R. 2020. Available online: https://www.r-project.org/. Accessed 10 October 2020.

32. QGIS. A free and open source geographic information system. QGIS. 2020. Available online: https://qgis.org/en/site/. Accessed 10 October 2020.

33. Senaviratna N, Cooray T. Diagnosing Multicollinearity of Logistic Regression Model. Asian Journal of Probability and Statistics. 2019:1-9.

34. Veenstra G. Race, gender, class, and sexual orientation: intersecting axes of inequality and self-rated health in Canada. International Journal for Equity in Health. 2011;10(1):3. doi:10.1186/1475-9276-10-3.

35. Zajic A. Intoduction to AIC - Akaike Information Criterion. Toward data science. 2019. Available online: https://towardsdatascience.com/introduction-to-aic-akaike-information-criterion-9c9ba1c96ced. Accessed 11 Nov 2020.

36. United Nations. The Millennium Development Goals Report 2015. UN. 2015. Available online: https://www.un.org/millenniumgoals/2015_MDG_Report/pdf/MDG\%202015\%20rev\%20(July\%201).pdf. Accessed 30 Nov 2020.

37. The Global Fund. Uganda. The Global Fund. 2020. Available online: https://www.theglobalfund.org/en/government/profiles/uganda/. Accessed 30 Nov 2020.

38. Fauci AS, Eisinger RW. PEPFAR - 15 Years and Counting the Lives Saved. New England Journal of Medicine. 2018;378(4):314-6. doi:10.1056/NEJMp1714773.

39. Odokonyero T, Mwesigye F. Healthcare coverage and equity - Towards Universal Health Care in Uganda. EPRC. 2017. Available online: http://154.72.196.19/sites/default/files/resources/Healthcare\%20coverage\%20and\%20equityTowards\%20Universal\%20Health\%20Care\%20in\%20Uganda.pdf. Accessed 30 Nov 2020.

40. Kabagenyi A, Reid A, Ntozi J, Atuyambe L. Socio-cultural inhibitors to use of modern contraceptive techniques in rural Uganda: a qualitative study. Pan Afr Med J. 2016;25:78-. doi:10.11604/pamj.2016.25.78.6613.

41. Avong NH. Relationship between religion and use of modern contraceptives among the Atyap in Kaduna State, Nigeria. Research on humanities and social sciences. 2012;2(8):82-9.

42. Agénor M. Future Directions for Incorporating Intersectionality Into Quantitative Population Health Research. American Journal of Public Health. 2020;110(6):803-6. doi:10.2105/AJPH.2020.305610.

43. Bowleg L, Bauer G. Invited Reflection: Quantifying Intersectionality. Psychology of Women Quarterly. 2016;40(3):337-41. doi:10.1177/0361684316654282.

44. Bowleg L. When Black + Lesbian + Woman $\neq$ Black Lesbian Woman: The Methodological Challenges of Qualitative and Quantitative Intersectionality Research. Sex Roles. 2008;59(5):312-25. doi:10.1007/s11199-008-9400-z.

45. Kwagala B, Galande J, Musimami P. DHS Working Papers. Disability, Partner Behaviors, and the Risk of Intimate Partner Violence in Uganda: Further Analaysis of the 2016 Demograhic and Health Survey. 
2019. Available online: https://dhsprogram.com/publications/publication-WP150-Working-Papers.cfm. Accessed 8 May 2020.

46. Muluneh MD, Stulz V, Francis L, Agho K. Gender Based Violence against Women in Sub-Saharan Africa: A Systematic Review and Meta-Analysis of Cross-Sectional Studies. International Journal of Environmental Research and Public Health. 2020;17(3):903.

47. Yount KM, Krause KH, Miedema SS. Preventing gender-based violence victimization in adolescent girls in lower-income countries: Systematic review of reviews. Social Science \& Medicine. 2017;192:1-13. doi:https://doi.org/10.1016/j.socscimed.2017.08.038.

48. Hancock A-M. When Multiplication Doesn't Equal Quick Addition: Examining Intersectionality as a Research Paradigm. Perspectives on Politics. 2007;5(1):63-79. doi:10.1017/S1537592707070065.

49. United Nations. Convention on the Rights of Persons with Disabilities. United Nations. 2006. Available online: http://www.un.org/disabilities/convention/conventionfull.shtml. Accessed 25 October 2015.

\section{Figures}

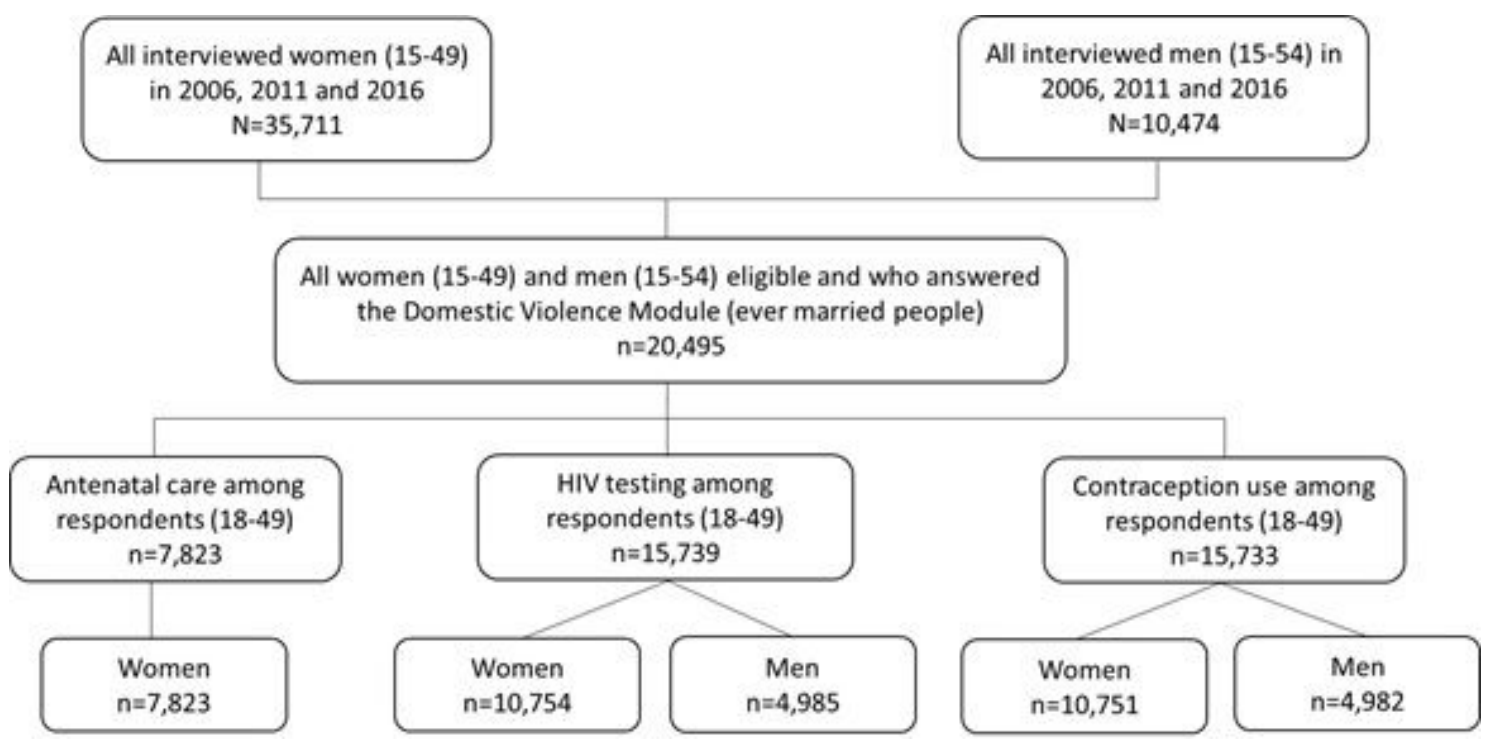

\section{Figure 1}

Study population 


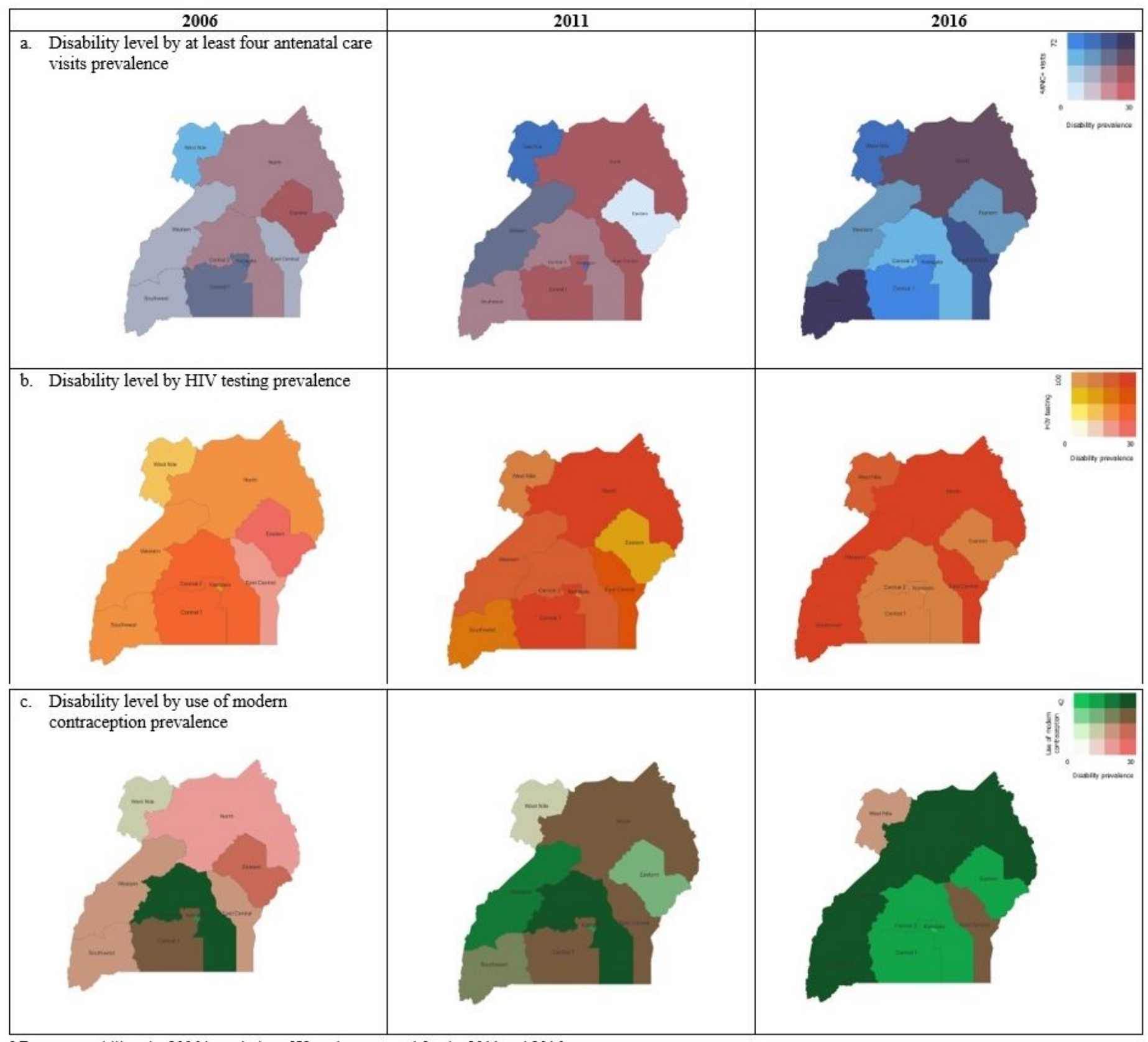

${ }^{2}$ For comparability, the 2006 boundaries of Uganda were used for the 2011 and 2016 maps.

\section{Figure 2}

Disability level by SRH service use prevalence in Uganda between 2006 to $2016 \mathrm{a}$ 